\title{
Facilitating Change, the Decision-maker's Views of Municipality Organized Food Distribution to Elderly People Living at Home and Suggestions for Development - A Participatory Action Research Study
}

\author{
Zada Pajalic $^{1,2}$, Lena Persson ${ }^{1}$, Kirsti Skovdahl ${ }^{2} \&$ Albert Westergren ${ }^{1}$ \\ ${ }^{1}$ The School of Health and Society, The PROCARE Group \& The Network for Eating and Nutrition, Kristianstad \\ University, Sweden \\ ${ }^{2}$ The School of Medical and Health Sciences, Örebro University, Sweden \\ Correspondence: Zada Pajalic, Kristianstad University, Elmetrpsvägen 15, 29188 Kristianstad, Sweden. E-mail: \\ zada.pajalic@hkr.se
}

\author{
Received: April 13, 2012 Accepted: May 4, 2012 Online Published: October 18, 2012 \\ doi:10.5539/par.v1n1p14 URL: http://dx.doi.org/10.5539/par.v1n1p14
}

The study was supported by The Kristianstad University and Skane County Council. The third author (AW) was supported by the Swedish Research Council and the Skane County Council.

\begin{abstract}
This study is the final part of a larger project with an action research approach focusing on food distribution (FD) within municipal service and care for elderly persons, living at home ( $\geq 65$ years), from various perspectives. The aim was to describe the decision-makers' the politicians and top level administrative manager's views on the FD service, and to give feedback from the results of earlier studies based on information given by FD receivers, the perspectives of involved professionals, and the results of an intervention study and further to report the decision-makers suggestions for which areas should be taken into consideration as starting points to improve the FD process and practice. Data was gathered in two steps: step 1, through individual interviews $(n=12)$ with the decision-makers during the spring of 2009, step 2a through feedback from previous studies, received during the autumn of 2011 and step $2 \mathrm{~b}$ from discussions based on the feedback. The interview data was analysed using qualitative content analysis. The findings indicated a discrepancy between the reality and the political visions. It was shown that decision-maker's needed to make decisions despite their uncertain knowledge of the complexity of the FD programme. They considered what has been, what is, and will be, when setting goals. Their goal was that elderly person's rights and needs should be fulfilled. This included freedom of choice and individual consideration. In addition, it meant, meeting elderly people's medical and social needs. Three areas were found to require facilitation for change related to FD: 1) the monitoring of the elderly's health and wellbeing while providing FD, 2) the increasing of professional competence, and 3) the creation of a forum for inter-professional communication. The findings in this study have implications for nursing, gerontology and public administration.
\end{abstract}

Keywords: action research, decision-makers, facilitation, food distribution, municipality

\section{Introduction}

This study was performed within a medium-sized municipality in southern Sweden, with about 80000 inhabitants. Approximately 650 older persons ( $\geq 65$ years) received municipal food distribution (FD) but this number varied during any week as some had FD less often than every day. Food was produced at a municipality owned kitchen. The diet manager had the overall responsibility for the food production and the personnel employed at the kitchens (Pajalic, Persson, Westergren, Berggren, \& Skovdahl, 2012b; Pajalic, Persson, Westergren, \& Skovdahl, 2012a). The municipal kitchen is subordinate to the municipal care and service administration which is led by the administrative manager who in turn is subordinate to the management committee represented by politicians (elected citizens' representatives, $\mathrm{n}=23$ ). The politicians are the highest level of decision making who focus on budget and policy matters. The administration manger has the responsibility to execute the politician's decisions and to see that they are put into operation by the responsible personnel.

To the best of our knowledge, there is no existing research focusing on the decision-makers' (DM) (politicians and 
administrative management levels) experiences of Food Distribution (FD, comparable to the international concept "Meals-on-wheels") carried out by a municipality, thereby the need for this study. The need for and right to FD emanates from a situation where a person, most often elderly, no longer can manage to obtain or cook food by themselves. Many people are involved in the FD process, from the politicians who make the political and economic decisions to the assistant nurses or taxi drivers who deliver the food. The decision-makers at different levels are committed to have impact on the FD process so their perspectives are important to hear. Systematic work with the decision-makers, involving them in research, and by giving feed-back of research findings from "the field" is a possible starting point for changing the FD process and practice. The decision-makers are empowered to make decisions regarding improving the FD process, which in turn can benefit the consumers, i.e. those who use the service.

\subsection{Background}

In Sweden, when an elderly person and even a younger person with health related impairments has difficulties to make food by themselves and cannot meet this need in other way, they have the right to apply for daily food distribution (FD) to their homes by their municipality (Social services act, 1981). The initiative for applying for FD can come from the person themselves their relatives and from the care personnel involved in helping and caring for the person concerned. The FD is a part of a complex organisation within the Swedish municipal care and service programme. The main objective regarding care and social service for the elderly (Lagergren, 2005) is that the elderly shall have access to good health care and social services in their own homes (Lagergren, et al., 2004; Nilsson, 2001). The municipalities have the overall responsibility for health care and social services; this refers to all of the public home care professionals' activities carried out in the elderly persons' homes (Andersson, Hallberg, \& Edberg, 2008; Thome, Dykes, \& Hallberg). The public home care professionals are : medically responsible nurses, registered nurses, assistant nurses, health care assistants, public home care officers and decision-makers at the political and administrative levels (Mattsson Sydner, 2002). A medically responsible nurse has the overall responsibility for quality and security in the health care and social services. Registered nurses are responsible for nursing services and also for coordinating and implementing nursing strategies and the supervision of the health care assistants (Gershater, Pilhammar, \& Roijer, 2011). Further registered nurses are directly involved in the assessment, planning and evaluation of nursing activities and their work is regulated by The Swedish Health and Medicine Service Act (Sahlin, 2000). The politicians are elected citizens with the role of representatives in the care committee for the care of the elderly. The assistant nurses, administrative professionals and public home care are governed by such legislation as the Swedish Social Services Act (Erman, 2001).

Planning of health care and social services is also dealt with under the Social Services Act (Erman, 2001) which stipulates that the municipalities shall plan services for elderly people. The management of the care and service programme, in a municipality, at the highest level, is performed primarily by the politicians (elected, citizens' representatives) who sit on the care and service committee. The politicians are responsible for overall strategy and performance management. The officials at management level have the responsibility to put the politician's decisions into operation (Montin, 2006). Municipal care varies between different municipalities regarding its organisation, depending on local political and financial frames (Hjelm, Rolfe, Bryar, Andersson, \& Fletcher, 2003; Janlöv, Hallberg, \& Petersson, 2011). The main characteristic of all care and social service is that it includes all citizens and is financed mainly through taxes but where the citizens pay about $10 \%$ of the total cost (Elmér, 2000; Pajalic, et al., 2012b). The FD is regulated by a decision making processes at government and municipal level. The state government dictates the general directions regarding how health care and social services shall be performed. However the general laws and regulations do not regulate in detail how the FD should be organised within a municipality which gives the possibility for each municipality to organise its FD based on its own specific circumstances (Rothenberg \& Lewald, 2006).

Studies in other areas indicate that systematic work with decision-makers and their involvement in developing processes is beneficial for the development of municipal health and care services (Meyer \& Davis, 2002; Nilsson, 2010). Despite the fact that FD in Sweden is regulated differently from that of other countries, there are several properties that are common (Pajalic, et al., 2012b). For instance, the grounds for requesting a service like FD, or the need for help with food are most likely similar in all countries. Care and service is governed by decision-makers at many levels (Pajalic, Springett, \& Dychawy-Rosner, 2007). A person in need of help with food is a person who is also at risk for improper food intake and needs to be monitored. There is no existing research focusing on municipal decision maker's views of the FD service to the elderly living at home and therefore this study is important. Through this research it might be possible to gain insight on how to improve the municipal FD service.

This study is the final part of a larger project using an action research (AR) approach (Meyer \& Davis, 2002), 
focusing on FD in municipal service and care for elderly persons living at home ( $\geq 65$ years) in the southern part of Sweden. The study is based on the different perspectives of the FD recipients (Pajalic, et al., 2012b), the various involved professionals in the FD chain (Pajalic, et al., 2012a) and participation based intervention for identifying development areas and improving FD practice (Pajalic, Persson, Westergren, \& Skovdahl, 2012c). This study shows that the FD service should not been seen as fragmentary social support. Also it shows that the fragmentation of the FD organisation has also led to some professionals taking more responsibility, informally, than they were supposed to or had the competence to do so. Further, the study shows that systematic work with motivated personnel involved in FD and their involvement in interventions is beneficial for changing the FD process and practice (Pajalic, et al., 2012b; Pajalic, et al., 2012c). Also highlighted in the study is the importance, in an action approach, that of involving the top level management i.e. decision makers (DM) including politicians and administrative management levels. Adding the DM's views, and using feed-back from previous studies in this field, can facilitate the goal of putting positive changes into practice.

\section{Aim}

The aim of this study was to describe DM's views on the FD service and report their suggestions for which areas should be taken into consideration as starting points to improve the FD process and practice.

\section{Method}

\subsection{Data Collection}

Data was gathered in steps: step 1 through individual interviews (Kvale, 2007) $(n=12)$ with the DM during the spring of 2009 and step 2a through feedback, from previous studies (Stringer \& Genat, 2004), gathered during the autumn of 2011 and step $2 \mathrm{~b}$ through discussions (Stringer \& Genat, 2004) based on the feedback. The interview data was analysed using qualitative content analysis (Burnard, 1991).

In step 1 the interviews began with two questions: Can you please tell me about what you consider to be important in the context of FD from your point of view and how do you see your own role in relation to FD? The interviews lasted between 45 and 60 minutes, were tape-recorded and transcribed verbatim.

Step 2a was feedback to the DM of findings from the previous studies in the project and included:

1. the various professionals' roles and responsibilities from being involved in FD (Pajalic, et al., 2012a)

2. the elderly persons experiences of receiving food distributed by the FD service (Pajalic, et al., 2012b)

3. participation based intervention for improving FD practice (Pajalic, et al., 2012c)

4. DM's views on the FD service and suggestions for which areas should be taken into consideration as starting points for changing the FD process and practice which was the subject of the first part of the present study.

Step $2 \mathrm{~b}$ was discussions based on the feedback from the participants and was rounded off with three questions: Can you describe what the concept "freedom of choice" means for you in connection to the FD service? How should the follow up and control of the FD service be performed? Which group, department persons, should have the overall responsibility for the management of FD The feedback discussions were led by the first author, (ZP) and documented by the second author (LP).

\subsection{Participants}

In step 1 the different levels of DM that had impact on or were responsible for the FD process were included. An initial information meeting with DM ( $\mathrm{n}=23$ ) was organised during the autumn of 2009 and the aim of this study was verbally presented. The verbal presentation was complemented with written information and forms for giving informed consent. Out of $n=23 \mathrm{DM}$ nine politicians, one medically responsible nurse and one administrative manager agreed to participate in individual interviews.

In steps $2 \mathrm{a}$ and $2 \mathrm{~b}$, the feedback and evaluation part of the study was led by the first author, PZ. All the invited DM $(\mathrm{n}=23)$ attended an ordinary committee meeting held during the autumn of 2011 and participated in the discussions related to feedback.

\subsection{Analysis Process of the Interview Material}

The individual interviews were analysed by using qualitative content analysis (Burnard, Gill, Stewart, Treasure, \& Chadwick, 2008). The analysis was performed in four steps; firstly the data were read independently by two co-authors (PZ \& WA), several times, as open-mindedly as possible, in order to gain a sense of the whole and to formulate ideas for further analysis. Secondly the text was divided into meaning units which were condensed and coded. The codes were reflected upon and sorted into sub-categories that, in third step, were sorted into categories. In total, two categories were identified: "To make decisions despite uncertain knowledge and a complex context", 
and "The goal is to fulfil the elderly person's rights and needs". As a fourth step, the content was reflected upon and discussed in the research group. A latent analysis was performed in order to grasp the underlying meaning in the text (Graneheim \& Lundman, 2004). Questions about the meaning in the text were "addressed to the text" in order to reveal the deeper structural meaning (Burnard, et al., 2008). The latent analysis consisted of dialectical movements between the whole and the parts, between understanding and explanation and between explanation and comprehension. A main theme was identified: "Reality versus political visions". All steps in the analysis were critically discussed. The findings were discussed in relation to the research question and agreed concerning the final description of the categories and the interpretation of the theme.

\section{Ethical Considerations}

This study was performed in accordance with the World Medical Association Declaration of Helsinki (Saif, 2000) and has been approved by the regional ethical review board in Lund, Sweden (LU09/365). All participants gave their informed consent to participate in the study after having been presented with detailed information about the study and the conditions for their participation; they were also informed that they had the right to terminate their participation at any time without it having any consequences for them.

\section{Results}

\subsection{Results from Step 1}

The overall theme "Reality versus political visions" described the DM insecurity in their own role of being at the highest decision maker's level. The overall impression was that the DM did have visions concerning how the FD service should be organised. Many of the participants pointed out the importance of the elderly's social needs during mealtimes but that the present FD model was actually a hindrance for this. They agreed that the organisation of the FD service should be created to meet individual needs and that there should be a variety of opportunities available for the elderly. The municipal economy and regulations were described as hindrances to realising the political visions. That the DM is often, part time voluntary politicians was also described as a hindrance. Many participants described limited time as the reason for their not having the full picture of the FD organisation, which meant that they were dependent on information from others to make their decisions

\subsubsection{Uncertain Knowledge Base for Decision Making}

When the DM spoke about the knowledge, required competence and possibilities available, they agreed that they do not have full insight into how extensive the FD organisation is and what competence is required to offer a good FD service "the experience one has is often via relatives or acquaintances". One of the participants noted that the decision making process is based on facts supplied by administrative officers one bases ones handling on the information received from the administration..... they are the people who one has to rely on" Some of the participants appeared to be sceptical towards experts; they viewed them as simple technocrats, focused only on monetary considerations and not on the meaning of the FD service to its recipients. They described these groups as self-opinionated and that they offer many complaints without particularly good reasons. The participants expressed that the decisions regarding FD should be taken by politicians and that they should be objective decisions without any involvement from the administrative officers, as one of them described it "one should remove the decision making process from administrators who say no for the wrong reasons. We need to take a politically comprehensive decision, however, there still remains an ideological question, and is it the politicians who shall make the decisions? "Other participant's expressed scepticism towards administrative officers on the basis because they do not have sufficient insight related to how they will actually put political decisions into operation within the organisation. Many participants expressed how they felt that the administrative officers used economic considerations as an indirect influential factor on which to make their decisions: One of the participants described it as "a question of principal not economy".

All of the participants expressed that they have the greatest trust in the personnel who are directly involved in the FD service and with the diet manager.

\subsubsection{Complex Context as a Base for Decision Making}

The participants agreed that their work is guided by the regulations "it requires an insight into how our taxes are used and what type of control mechanism sabotages any positive outcome".

Some of the participants experienced that the FD organization appears to be more bureaucratic than democratic. Further they agreed that the FD organization is too regulated so that it is mostly steered by managers while the role of the politicians is weak "politicians today, both communal and regional, pass over their responsibilities to the administrators instead of taking political decisions that they are prepared to stand for instead they pass on the responsibility to deal with a question to an administrator". Further on. 
"Therefore I don't think that the elderly should be answerable. How do I question a decision made by someone I am not able to question only to find myself in a bureaucracy instead of a democracy?"

When DM talked about the FD organisation's responsibility they pointed at society's responsibility towards its citizens, their well-being, and the prevention of the consequences of the intake of improper food. They highlighted that they as politicians are chosen by society and that they are the citizen's voice in the municipal care organisation under whose umbrella the FD is organised. The participants described that the most important basis for decision making is to capture a correct picture of how the FD service works in reality. To gain insight into the reality, they described the value of having the possibility to visit some parts of the FD chain and to follow the FD service from the preparation of the food through to accompanying an elderly person during their meal, and actually order and taste the food themselves. Even if the decision-makers had this possibility there was only one of them who adopted to use this opportunity. One of the participants expressed that" we, who decide, know how things are in reality and we also have the responsible politicians ... unfortunately it doesn't work here... I cannot say that I know so very much about it..."

\subsubsection{Considering What Has Been, Is, and Will Be When Setting Goals}

All DM agreed that the food preparation service to the elderly in their homes that was available some years ago was better. Unfortunately this service was taken away at the same time the government legislated that the elderly should be able to remain living in their own homes for a long as possible, supported by external services such as the FD service which was considered to be the most economical solution to meet the nutritional needs of the elderly. One participant expressed it as "Suddenly it became, so to say, the mode to remain living in ones own home and it was expected that the elderly wished to live at home".

Several participants expressed that the principle of the elderly living in their own homes for as long as possible is old-fashioned and needs to be reconsidered and another alternative, "sheltered homes" was given as a good example: "One should perhaps think in a new way and build apartments for the elderly with a day-centre and dining rooms". The DM talked about social meeting-points that should be a complement to the FD service and play an important support role to facilitate social exchange. One of participants expressed it as "There should be the possibility for the elderly to visit a day-centre to take their meals". All of the participants agreed that no one should eat alone involuntarily.

When the DM compared the present FD service with how it was earlier, all of them agreed that the former food related service with daily food making assistance in the elderly people's homes was the better alternative "Then the pensioner could smell the food being prepared and have a chat with the personnel". The former service offered something that nowadays is lost, i.e. that the personnel become natural company for the pensioners while preparing their meals. Further the food preparation in the elderly's homes, with the smell of cooking, could influence their appetite. They agreed that this kind of service was a more holistic alternative because it made it possible for the personnel to gain a better picture of the elderly person's food intake.

When the participants compared the former service arrangement with the one offered today, they realised that getting the full picture and follow-up of the FD service is difficult today as all parts in the FD chain are now segmented. One of the participants described this as "then there are many who only receive the food delivery service, there is no one who checks what they have eaten".

The DM explained the future prognosis taken from demographical surveys showing the coming generation's lifestyle which is quite different from today's situation. In future their demands will challenge the FD service. The DM pointed out that food had another meaning for the older generation who were taught to respect food and not to leave it uneaten. Further the DM explained that the recent generation of pensioners, those born in the 1940s, demand new thinking in relation to care and service as this generation is one who has enjoyed the best living conditions, a good economy and has developed broader food habits, one participant said: "now it will be different, we who were born in the 40s will undoubtedly be more demanding and will not tolerate just anything". Another demographical change that the participants took into consideration was that today Swedish society is more multicultural in comparison to 20 years ago. They pointed out that the FD service should be more tailored, and able to meet the various food cultures demands. One of them expressed it as "people from other cultures have a different food tradition to that which is classically Swedish".

\subsubsection{Freedom of Choice and Individualisation as Political Lodestars}

The participants told that the honour concept of "freedom of choice" seems to be misused, as in fact the choice actually is only between accepting or not accepting the FD service they have been granted. For some participants, freedom of choice should mean that elderly people can choose other producers of food than those supplying the 
public sector i.e. municipalities. One of the participants expressed it as "it is an economic question for all the municipalities ......you take the solution that is most economically viable". Because the FD service is part of the public service and financed by taxes, this cannot be something that citizens just can simply wish to receive. To be granted the FD service each applicant must go through a need assessment's procedure. The participants expressed that they trust the public home care officers' judgment as they are described as being professional in doing need assessments and that they can see people's needs, but at the same time they can also see what resources are available. Further, the participants stated that it is about the individual assessments which they as decision- makers cannot steer. They agreed that setting the overall framework for the FD service is on the political decision level and how this framework should be put into operation in the practice is the task of a manager at the administrative official level. This was expressed as "we discuss...guidelines for the division of responsibility in the FD chain... and how the distribution shall be carried out".

\subsubsection{Medical and Social Perspectives of Food Distribution}

The DM described that FD is both a social and a medical intervention aimed at preventing improper food intake among elderly people living at home. The FD service shall assure "a reasonable standard of living" in accordance with the accepted Swedish standard of living. Some of the participants noted that the concept of a "reasonable standard of living" left space for a number of interpretations. Further, they explained that depending on who interprets this concept the result can be inequalities in assessments and approvals at an individual level. The participants reasoned, for example, that the FD service is presented as an intervention to satisfy a "reasonable standard of living" for the elderly living at home. However the participants believe that a correct interpretation of this concept is not met by the present FD service procedures when it comes to providing for the FD receiver's social needs during mealtimes. When the DM reflected over the FD service and its effects on social events during mealtimes, four of the participating DM stated that they could not see themselves as receivers of the FD service, thus indicating that they would reject the very service that they actually make decisions about.

\subsubsection{Facilitating Change}

The discussions after the feedback of the findings from the interviews and previous studies resulted in an overall agreement that loneliness among the elderly FD receivers is one of the greatest problems. Various ideas and questions were put forward, such as; does their loneliness depend on the elderly people's choice to live at home, and have some of these people tried to apply for the nursing homes? Further, those who distribute the food should stay and be company for the elderly during their meals and is loneliness experienced in the same way if the pensioners live in rural or city areas? The DM agreed that it is important to provide meeting places and to help the elderly with transport to these places where they could receive meals that they could enjoy in the company of others, thus providing a scenario for making social relationships within secure conditions.

Three areas were highlighted as needing facilities for change with focus on FD:

1) The monitoring of the consumer's health and wellbeing following the provision of FD,

2) Increasing professional competence, and 3) the creation of a forum for inter professional communication. The participants believed that the public home care officer's decisions should be reported to the district nurses in order for them to follow up on the effects of the FD service on an elderly person's health and wellbeing. They identified the fact that the elderly who only receive meals but have no contact with the assistant nurses are the most exposed group. With respect to increasing professional competence, it was announced that, due to the present study, one full time post as a dietician has already been filled. The explanation was; that during the present study the need for this competence had become obvious to the decision-makers, and that the quality and content of the meals should be on the agenda to a greater extent. In addition, an administrative manager clarified that the various professionals needed an "FD forum" for inter-communication as such a forum that is contributed to by a wide range of personnel, would help the DM gain a comprehensive view over the whole FD service chain.

\section{Discussion}

The present study was inspired by the action research (AR) approach (Stringer \& Genat, 2004). With an AR approach representatives from the decision making level of an organisation are used by researchers to facilitate the identification of problems and requested to suggest solutions that will improve practice. In an AR approach, it is important that the participants are willing to play an active role in the research process and in the planning of future changes (Stringer \& Genat, 2004). In this study, the research process plan was continuously negotiated with the participants in agreement with the ethical principles for medical research involving human subjects (Saif, 2000; Williamson \& Prosser). The researcher (PZ) focused on gaining the participants trust and assuring them that she regarded them as equals, which demonstrates an important feature of the AR approach, namely democratic 
incitement (Kilbride, Perry, Flatley, Turner, \& Meyer, 2011). The researcher worked as facilitator of change, consulting with the participants as to how the action process could be evaluated (Kitson et al., 2008). The role of the first author (PZ) was to be a collaborator through working with the participants and adapting the research project in accordance with the continuously changing everyday practice (Strelioff, Lavoie-Tremblay, \& Barton, 2007). The process of facilitation is multifaceted and can be described as a range of roles that aim towards implementing new collectively developed knowledge into practice. This requires flexibility and the ability to combine different techniques (Kitson, et al., 2008). This process depends upon the facilitator carrying out the roles required to help and enable participants to reflect on and change their practice.

This way of working, and its outcomes, becomes meaningful to participants once they become an active partner in taking decisions about the next stage of the programme (Meyer, Pope, \& Mays, 2000). The facilitation and evaluation discussions were open, and knowledge, ideas and opinions were exchanged freely. The participants reflected over the previous results and made suggestions for change. This was interpreted as empowerment. By taking an active part in the process, and reflecting over the FD service, the participants became aware that the present FD organisation may negatively influence the social dimension of the elderly's mealtimes. The participants also saw that the absence of follow-up routines for the FD service and its possible effects on elderly peoples' health and well-being was something they needed to do something about.

Findings from this study can be evaluated in terms of trustworthiness, credibility, dependability, conformability and transferability (Lincoln \& Guba, 1985).Credibility was assured by presenting views from different participants in order to capture their different experiences, and by the fact that two co-authors (PZ \&WA) were involved in the analysis. The facilitation for change was performed by the first author and the second author PL was the observer for the whole process. All participants involved in the facilitating process were given the possibility to discuss the findings and suggest actions for change (Stringer \& Genat, 2004). Dependability was assured by the fact that the same researcher, the first author, carried out all the interviews and transcriptions. The use of a tape-recorder and verbatim transcripts, as well as referring back to and re-reading the transcripts during the analysis process, allowed the researchers to remain close to the text. The citations make it possible to assure conformability. Transferability can be considered to be achieved if the present results can be recognised and transferred to comparable contexts (Lincoln \& Guba, 1985).

The aim of this study was to describe decision makers' (DM) views on a municipal FD service and report their suggestions for which areas should be taken in consideration as starting points for changing the FD process and practice. The main findings in the study are that the DM are positioned were they have limited knowledge about the FD service and have to balance their decisions based on the available resources verses their visions. Further DM agreed that the FD service is complex and they need to take into consideration what has been, what is and what will be when setting their goals to fulfil the needs of FD receivers. This means that FD practice needs a tool for bridging the gaps between theory, research and practice (Jerlock, Falk, \& Severinsson, 2003). Further, successful involvement of the FD personnel, at all levels, requires evidence based feed-back of their findings to be evaluated and put into practice (McCormack et al., 2002). The Swedish welfare sector changes constantly, and it is important to follow these changes and tailor new methods at the same pace (Bergmark, 2000). The Swedish welfare philosophy is that the power relations should be based on solidarity (Subasic, Reynolds, \& Turner, 2008). On the other hand it was found that the social and care system has a tendency to be more mechanistic with regards to financial control as a result of the "top-down" organisation tradition. As a consequence of this type of organisation the various involved professionals become divided into teams which results in difficulties for them to establish communication between each other (Wihlman, Lundborg, Holmstrom, \& Axelsson, 2011).

The politicians had views and visions about what the FD service was meant to fulfil for the elderly, i.e. their rights, medical and social needs, individual consideration, and freedom of choice. The decision-makers agreed that it is important to focus on both the practical and psychological needs of the elderly. Their reflections were mainly based on the feed-back regarding the FD receiver's positive experiences of having the possibility to influence menus or choose between dishes, however they need also to take into consideration the elderly's fear of being isolated (Pajalic, et al., 2012b). In another study, involving the social and care receivers was found to be a way to increase the autonomy of the elderly and further important for the work of the care giving organisations (Holmström \& Röing, 2010).

In the present study, the discussions, after feedback, focused on the proposal that a comprehensive view over the whole FD chain and the involved professionals' competence in nutrition should be put on the agenda. Further the participants agreed that a forum for inter-professional communication is required. It was shown that competence in nutrition includes knowledge that enables the involved professionals to identify and evaluate varying nutrition related situations, thus giving them the ability to use this knowledge in any situation (Southgate, Keller, \& Reimer, 
2010). Further, the service and care sector is expanding and during the last decades the Swedish service and care sector has carried out extensive changes. The main reason for these changes has been an economic situation that demands less costly service and care forms. Tighter economic conditions created the need for rationalisation (Åhgren, 2007). The division of service and care is at both an organisational and professional level, due to there being two different sets of regulations that determine their respective responsibilities. The organisational rationalisation has focused on the delegation of extensive responsibilities to frontline mangers. Further, the other change that influenced the social and care sector was the process through which the profession was transformed by making a clear definition of what is the content of competence and professional integrity. Further this process of professionalization led to various professional groups being left to work with a high level of autonomy, independence and personal responsibility. At the same time this process created a hierarchical gap between the various professions which make it difficult to communicate between the different professionals and organisation levels (Ahgren, 2003). Further the professionalization process is exposed to constant changes in the service and care sector and the demands to adapt to new conditions. The consequences of these processes are that the professionals experience their work situations as stressful and with limited control of the work situation (Carpenter et al., 2004). The various professionals in the social and care sector are dependent on collaboration (Nilsson, A., 2001). Conclusively, the involved professionals must have sufficient professional knowledge to be able to act independently and offer high quality service and care including the FD service. As many of the professionals work alone, to a large extent, they must have the possibility to reflect independently and in collaboration with other professionals involved in FD, and be able to make decisions and assess strategies that are appropriate for any specific FD related situation. Since the FD service, that was used as a study object in the present project, has shown to be a complex process consisting of several parts, it is important to create a forum for inter-professional communication focusing on FD. This may bridge the gap between the professionals, and the theory and the research that is involved in the context of FD.

\section{Conclusion}

This study shows that systematic work with the decision-makers and their involvement in the developing processes is beneficial and can also be a starting point to improve the FD process and practice. Further the present study shows that are very important to focus on continuously developing the professionals' knowledge in nutrition, their inter-professional communication and their comprehensive view over whole FD chain. To sum up, the present study gives a picture of the complexity of the FD chain and that the involvement of all levels in this organisation is a precondition for the development of the municipal FD service. The findings in this study have implications for nursing, gerontology, public administration, public service and care development and in the care for the elderly.

\section{Acknowledgements}

We are grateful to all the participants for their interesting input and inspiring dialogue. Thanks to Karin Pettersson and The Kristianstad Municipality for welcoming this research. The study was connected by Zada Pajalic and Albert Westergren to the Patient-Reported Outcomes- Clinical Assessment, Research (PRO-CARE) Group and The Network for Eating (Nätverket för Ätande och Näring, NÄVER). Further Zada Pajalic is member of The Action Learning, Action Research Association (ALARA) Australia.

\section{Contributions}

1) Study design and acquisition of the data ZP; 2) Analysis and interpretation of the data ZP \& AW; 3) Drafting and critical revision of the manuscript ZP, LP, KS \& AW; who have also given their approval of the version to be published.

\section{References}

Ahgren, B. (2003). Chain of care development in Sweden: results of a national study. International Journal Of Integrated Care, 7, 3, $\mathrm{e} 01$.

Andersson, M., Hallberg, I. R., \& Edberg, A. K. (2008). Old people receiving municipal care, their experiences of what constitutes a good life in the last phase of life: a qualitative study. International Journal Of Nursing Studies, 45(6), 818-828. http://dx.doi.org/10.1016/j.ijnurstu.2007.04.003

Bergmark, A. (2000). Solidarity in Swedish welfare standing the test of time? Health Care Analysis: Journal Of Health Philosophy And Policy, 8(4), 395-411. http://dx.doi.org/10.1023/A:1026551420141

Burnard, P. (1991). A method of analysing interview transcripts in qualitative research. Nurse Education Today, 11(6), 461-466. http://dx.doi.org/10.1016/0260-6917(91)90009-Y

Burnard, P., Gill, P., Stewart, K., Treasure, E., \& Chadwick, B. (2008). Analysing and presenting qualitative data. 
British Dental Journal, 204(8), 429-432. http://dx.doi.org/10.1038/sj.bdj.2008.292

Carpenter, I., Gambassi, G., Topinkova, E., Schroll, M., Finne-Soveri, H., Henrard, J.-C., Bernabei, R. (2004). Community care in Europe. The Aged in Home Care project (AdHOC). Aging Clinical And Experimental Research, 16(4), 259-269.

Elmér, Å. (2000). Swedish social politics. Lund: Studentlitteratur.

Erman, M. (2001). Social Services Act: a guideline: Social Service Act with comments and practical directions. Stockholm: Svenska kommunförbdet.

Gershater, M. A., Pilhammar, E., \& Roijer, C. A. (2011). Documentation of diabetes care in home nursing service in a Swedish municipality: a cross-sectional study on nurses' documentation. Scandinavian Journal Of Caring Sciences, 25(2), 220-226. http://dx.doi.org/10.1111/j.1471-6712.2010.00812.x

Graneheim, U. H., \& Lundman, B. (2004). Qualitative content analysis in nursing research: concepts, procedures and measures to achieve trustworthiness. Nurse Education Today, 24(2). http://dx.doi.org/105-112. 10.1016/j.nedt.2003.10.001

Hjelm, K., Rolfe, M., Bryar, R. M., Andersson, B. L., \& Fletcher, M. (2003). Management of chronic leg ulcers by nurses working in the community in Sweden and the UK. Journal Of Wound Care, 12(3), 93-98.

Holmström, I., \& Röing, M. (2010). The relation between patient-centeredness and patient empowerment: A discussion on concepts. Patient Education And Counseling, 79(2), 167-172. http://dx.doi.org/10.1016/j.pec.2009.08.008

Janlöv, A. C., Hallberg, I. R., \& Petersson, K. (2011). Care managers' view of family influence on needs assessment of older people. Scandinavian Journal Of Caring Sciences, 25(2), 243-252. http://dx.doi.org/10.1111/j.1471-6712.2010.00818.x

Jerlock, M., Falk, K., \& Severinsson, E. (2003). Academic nursing education guidelines: tool for bridging the gap between theory, research and practice. Nursing \& Health Sciences, 5(3), 219-228. http://dx.doi.org/10.1046/j.1442-2018.2003.00156.x

Kilbride, C., Perry, L., Flatley, M., Turner, E., \& Meyer, J. (2011). Developing theory and practice: creation of a Community of Practice through. Journal Of Interprofessional Care, 25(2), 91-97. http://dx.doi.org/10.3109/13561820.2010.483024

Kitson, A. L., Rycroft-Malone, J., Harvey, G., McCormack, B., Seers, K., \& Titchen, A. (2008). Evaluating the successful implementation of evidence into practice using the PARiHS framework: theoretical and practical challenges. Implementation Science, 3, 1-1. http://dx.doi.org/10.1186/1748-5908-3-1

Kvale, S. (2007). Doing interviews. Thousand Oaks, Calif.: Sage Publications.

Lagergren, M. (2005). What happened to the care of older persons in Sweden? A retrospective analysis based upon simulation model calculations, 1985-2000. Health Policy, 74(3), 314-324. http://dx.doi.org/10.1016/j.healthpol.2005.01.022

Lagergren, M., Fratiglioni, L., Hallberg, I. R., Berglund, J., Elmståhl, S., Hagberg, B., \& Wimo, A. (2004). A longitudinal study integrating population, care and social services data. The Swedish National study on Aging and Care (SNAC). Aging Clinical And Experimental Research, 16(2), 158-168.

Lincoln, Y. S., \& Guba, E. G. (1985). Naturalistic inquiry. Beverly Hills, Calif.: Sage.

Mattsson Sydner, Y. (2002). The unempowered meal - about food and maeals in the elderly-care. Doctoral Thesis Uppsala University: Institutionen för hushållsvetenskap, Upsala University.

McCormack, B., Kitson, A., Harvey, G., Rycroft-Malone, J., Titchen, A., \& Seers, K. (2002). Getting evidence into practice: the meaning of "context". Journal Of Advanced Nursing, 38(1), 94-104. http://dx.doi.org/10.1046/j.1365-2648.2002.02150.x

Meyer, J., \& Davis, E. (2002). Workplace chaplains: filling a need traditional EAPs can't meet. Benefits Quarterly, 18(3), 22-26.

Meyer, J., Pope, C., \& Mays, N. (2000). Using qualitative methods in health related action research. British Medical Journal, 320(7228), 178. http://dx.doi.org/10.1136/bmj.320.7228.178

Montin, S. (2006). Political steering and democracy in municipalities: eight dilemmas in one historical perspective. Stockholm: Sveriges kommuner och landsting. 
Nilsson, A. (2001). The nursing and caring comptence in the home-care. Doctoral Thesis Göteborg: Acta Universitatis Gothoburgensis.

Nilsson, P. (2010). Enhance your workplace!: A dialogue tool for workplace health promotion with a salutogenic approach. Doctoral Thesis Malmö: Institution of Clinical Science, Malmö, Lund University.

Pajalic, Z., Persson, L., Westergren, A., Berggren, V., \& Skovdahl, K. (2012b). The Experiences of Elderly People Living at Home Related to Their Receiving Meals Distributed by a Municipality in Sweden. Journal of Food Research, 1(1), 68. http://dx.doi.org/10.5539/jfr.v1n1p68

Pajalic, Z., Persson, L., Westergren, A., \& Skovdahl, K. (2012a). Public home care professionals' experiences of being involved in food distribution to home-living elderly people in Sweden-a qualitative study with an action research approach. Journal of Nursing Education and Practice, 2(2), 41. http://dx.doi.org/10.5430/jnep.v2n2px

Pajalic, Z., Persson, L., Westergren, A., \& Skovdahl, K. (2012c). Particaiptory based intervention for identifying developmental areas and improving food distribution practice - a particiaptory action research study (in manus).

Pajalic, Z., Springett, J., \& Dychawy-Rosner, I. (2007). Ensuring a receptive context for participatory action research as a vehicle for change: the example of community assistance for the elderly in Sweden. Conference Paper, peer reviewed, Action Research Conference at Work Research Institute, Oslo, September 2007, Action Research in Health Care, AFI Making the Practical Turn: Collaboration Across Nationalities, Professions and Varieties of Action Research, 3. http://urn.kb.se/resolve?urn=urn:nbn:se:hkr:diva-7951

Rothenberg, E., \& Lewald, B. (2006). Näringslära. (in English: Nutrition science). Årsta: Recip.

Sahlin, J. (2000). The Health and Care law: with comments. Stockholm: Norstedts juridik.

Saif, M. (2000). World Medical Association Declaration of Helsinki: Ethical principles for medical research involving human subjects. Journal Of American Medical Association, 284, 3043-3045. http://dx.doi.org/10.1001/jama.284.23.3043

Social Services Act. (1981). Stockholm: Ministry of health and social affairs, International secretariat.

Southgate, K. M., Keller, H. H., \& Reimer, H. D. (2010). Determining knowledge and behaviour change after nutrition screening among older. Canadian Journal Of Dietetic Practice Research, 71(3), 128-33. http://dx.doi.org/10.3148/71.3.2010.128

Strelioff, W., Lavoie-Tremblay, M., \& Barton, M. (2007). Collaborating to embrace evidence-informed management practices within Canada's. Healthcare Paper, 7, Spec, 36-41.

Stringer, E. T., \& Genat, W. J. (2004). Action research in health. Upper Saddle River, N.J.: Merrill Prentice Hall.

Subasic, E., Reynolds, K. J., \& Turner, J. C. (2008). The political solidarity model of social change: dynamics of self-categorization. Personality and Social Psycholgy Review, 12(4), 330-52. doi: $10.1177 / 1088868308323223$

Thome, B., Dykes, A. K., \& Hallberg, I. R. (2003). Home care with regard to definition, care recipients, content and outcome. Journal Of Clinical Nursing, 12(6), 860-72.

Wihlman, U., Lundborg, C. S., Holmstrom, I., \& Axelsson, R. (2011). Organizing vocational rehabilitation through interorganizational integration. International Journal Of Health Plann and Management, 26(3), 169-85. http://dx.doi.org/10.1002/hpm.1067

Williamson, G. R., \& Prosser, S. (2002). Action research: politics, ethics and participation.Journal Of Advanced Nursing,40(5), 587-93. http://dx.doi.org/10.1046/j.1365-2648.2002.02416.x

Åhgren, B. (2007). Creating integrated health care. Göteborg: NHV - Nordic School of Public Health. 